\title{
8
}
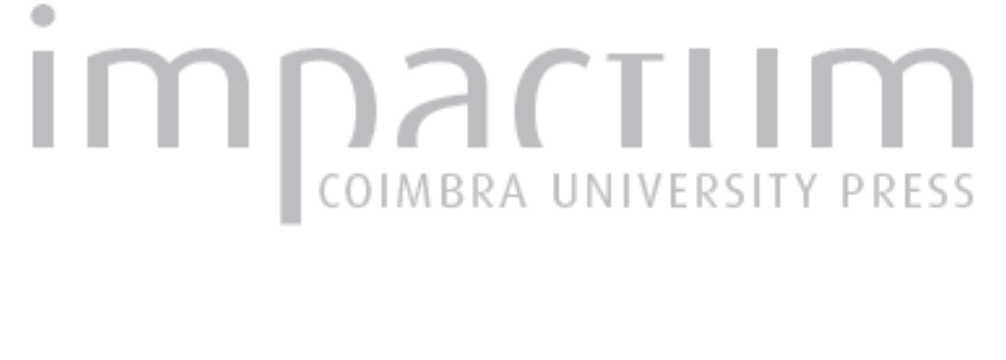

\section{Filosofia da educação conimbricense: sobre o "De Magistro" de Sebastião do Couto ( no curso Aristotélico Jesuíta de Coimbra, 1606)}

Autor(es): $\quad$ Carvalho, Mário Santiago de Publicado por: Faculdade de Letras da Universidade de Coimbra, Instituto de Estudos

URL

persistente:

DOI: $\quad$ DOI:http://dx.doi.org/10.14195/0872-0851_47_7

Accessed : $\quad$ 26-Apr-2023 15:17:39

A navegação consulta e descarregamento dos títulos inseridos nas Bibliotecas Digitais UC Digitalis, UC Pombalina e UC Impactum, pressupõem a aceitação plena e sem reservas dos Termos e Condições de Uso destas Bibliotecas Digitais, disponíveis em https://digitalis.uc.pt/pt-pt/termos.

Conforme exposto nos referidos Termos e Condições de Uso, o descarregamento de títulos de acesso restrito requer uma licença válida de autorização devendo o utilizador aceder ao(s) documento(s) a partir de um endereço de IP da instituição detentora da supramencionada licença.

Ao utilizador é apenas permitido o descarregamento para uso pessoal, pelo que o emprego do(s) título(s) descarregado(s) para outro fim, designadamente comercial, carece de autorização do respetivo autor ou editor da obra.

Na medida em que todas as obras da UC Digitalis se encontram protegidas pelo Código do Direito de Autor e Direitos Conexos e demais legislação aplicável, toda a cópia, parcial ou total, deste documento, nos casos em que é legalmente admitida, deverá conter ou fazer-se acompanhar por este aviso. 


\section{REVISTA FILOSÓFICA COIMBRA}

vol. 24 - número 47- março 2015

vol. 24 - número 47- março 2015

Fundação Eng. António de Almeida

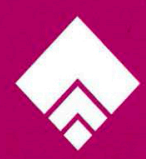




\title{
FILOSOFIA DA EDUCAÇÃO CONIMBRICENSE Sobre o "De Magistro" de Sebastião do Couto (no Curso Aristotélico Jesuíta de Coimbra, 1606)
}

\author{
MÁRIO SANTIAGO DE CARVALHO*
}

\begin{abstract}
Resumo: Para a instauração de uma filosofia moderna da educação foi necessário o aparecimento de uma ontologia não semiótica, e a alteração da teoria do conhecimento por anamnese, concomitantemente a uma doutrina da causalidade capaz de conferir ao mundo toda a autonomia que este deve ter. Depois de uma breve referência à extensa tradição propulsada pelo "Curso Aristotélico Jesuíta de Coimbra" (sobretudo Platão, Agostinho, e Tomás de Aquino) este artigo explica os elementos mais importantes que poderão ter contribuído para essa instauração, em resumo: uma ontologia aristotélica que naturalizou o mundo, uma epistemologia articulada com uma teoria da ciência muito precisa, uma antropologia que contempla já o telos de todo o processo educativo, o aluno. O professor, tal como o conhecemos, nasce assim pela crescente obliteração de Deus, mas o lugar do aluno, enquanto tal, só pode surgir ali onde o aprofundamento radical da complexa tarefa do professor se enxerta na explícita adoção de uma filosofia fundamental. Porém, a receção desta aquisição escolar está longe de ser isenta de ameaças.
\end{abstract}

Palavras-chave: Filosofia da educação, Aristotelismo Conimbricense, Platão, Agostinho, Boaventura, Aquino, Ensino, Escola.

Abstract: In order to found a modern philosophy of education a non-semiotic ontology was necessary, and the change of a theory of knowledge by anamnesis, concomitant to a doctrine of causality being able to give the world all its necessary autonomy. After a brief reference to the long tradition worked by the "Coimbra Jesuit Aristotelian Course" (especially Plato, Augustine, and Aquinas) this article highlights the most important elements that may have contributed to such founding, in short: an Aristotelian ontology that has naturalized the world, an epistemology

* Professor do Departamento de Filosofia, Comunicação e Informação da FLUP; membro da U.I.\& D. LIF (FLUP); mscarvalho@fl.uc.pt 
closely connected to a very precise theory of science, an anthropology already focusing the telos of the whole educational process, the student. The teacher, as we know him, is born due to growing obliteration of God, but the place of the student, as such, can only come up if the complex teacher's task is grounded on the explicit adoption of a fundamental philosophy. But the contemporary outcome of this achievement is no exempt of threats.

Keywords: Philosophy of Education, Coimbra Aristotelianism, Plato, Augustine, Aquinas, Bonaventure, Teaching, School.

1. Se alguma nota característica do humano se salienta, desde tempos remotos até aos nossos dias, é a educação. Acresce que o Homem é o único animal que se educa através de um processo socialmente regulado, a escola. Ora nunca, como nos dias de hoje, esta foi tão avassaladoramente omnipresente. Será uma banalidade dizer-se que a criança que entra na escola, cada vez mais cedo, corre igualmente cada vez mais o risco de morrer na escola. O prolongamento da chamada "escolaridade obrigatória" e a crescente desvalorização dos diplomas universitários - pavlovianamente compensada pelo acréscimo de graus quantas vezes justificado pela vertigem da "especialização" que ao mesmo tempo pode acalentar a menorização e aumentar a irresponsabilidade social que diminuem a possibilidade ativa da intervenção compensada de cada indivíduo na sociedade -, é a face mais visível da presente situação de acéfala panescolarização.

Há (houve) evidentemente uma educação não escolar, e quando nos volvemos para a reflexão filosófica sobre a educação deparamo-nos facilmente com dois textos antigos, um de Platão outro de S. Agostinho, aliás numa mesma linhagem, que acolhem palavras que dão que pensar a respeito do valor e do horizonte mais radical da educação - pela vertente do ensinável - e nos concitam irremediavelmente a pôr em causa a importância da escola e o seu mais pragmático ou técnico horizonte. O Ménon (390/385) e $O$ Mestre (389) daqueles dois tão grandiosos pensadores são textos "antigos", evidentemente, pelo que haveria que começar por reapreciar a valorização da escola no seu próprio tempo, contexto e lugar. Por exemplo, a Universidade transfronteiriça de Duzentos. Justamente, quando Tomás de Aquino compõe, nesta última instituição, o seu próprio $O$ Mestre (1256/59), essa valorização há de comparecer pela oposição ao horizonte dos dois textos antigos, o que equivale a dizer, sobretudo pela instauração do papel do docente, algo paralela a uma cada vez mais inequívoca educational turn. Não nos repugnaria pensar a aventura abelardina como um dos momentos prévios cruciais a contribuir para este desfecho", quer dizer-se: depois da "presunção" de Pedro

${ }^{1}$ Cf. Mário Santiago de Carvalho, Lógica e Paixão. Abelardo e os Universais (Coimbra: MinervaCoimbra, 2001). 
Abelardo jamais qualquer aluno que se prezasse eximir-se-ia a emular o seu mestre, a querer ao menos ser como ele, ou - o que quantas vezes pode ser pior - simplesmente a ocupar o seu lugar. Aquela preocupação ganhou raízes e rasgou séculos. Uma experiência quiçá repetível apesar de subjetiva tem sugerido empírica mas reforçadamente como na origem da vocação de um docente está outro docente ${ }^{2}$.

O gesto tomasino de Duzentos é tanto mais relevante quanto, no mesmo período e no mesmo contexto escolar, o de uma fulgurante Universidade parisiense, o seu colega Boaventura pronunciava-se ainda pela manutenção de tão velho e consistente paradigma. Não se pode deixar de insistir, a tal propósito e para a sua mais cabal interpretação, na relevância de um estudo de 1926 de E. Gilson em que o paradigma Tomás se opõe frontalmente ao paradigma Agostinho ${ }^{3}$. Daí para a frente a crescente importância do professor caminhará a par com a necessária admissão da possibilidade de ensinar-se anunciando, ou inventando até, esta possibilidade, e o seu próprio terreno e cultura, a tecnicização do ensino tal como hoje a acabamos por receber (mesmo que invertendo-se ou reequacionando-se uma qualquer pedagogia vertical ou diretiva até chegarmos às empolgadas e faustosas ciências da educação). Tal como Pedro Abelardo encenava no seu tempo, a escola, precisamente como a conhecemos, surge com o superior lugar do professor e não do aluno.

Vêm estas brevíssimas palavras a propósito do que resolvemos chamar, por comodidade, "a filosofia da educação conimbricense" que se desenvolverá explicitamente nos termos de uma "peripatetica docendi methodus" (q. 1 a.1 p. 291), quer dizer, construída na esteira de uma longa tradição aristotélica. Passando a explicar o escopo do vertente artigo: dado o prestígio e a difusão internacionais que o chamado Curso Aristotélico Jesuita de Coimbra (doravante: CAJC) conheceu; dado o facto de, nas páginas do mesmo Curso, Sebastião do Couto ter refletido explicitamente sobre o triângulo acabado de traçar, chegando a superá-lo (evocar-se-ão, mesmo assim, de passagem, algumas laudas do confrade Manuel de Góis, coautor e ainda maior responsável pelo CAJC); tendo presente, por fim, o papel moderníssimo que a Companhia de Jesus desempenhou na ação educativa (lembre-se esse monumento educativo conhecido por Ratio Studiorum), impunha-se a revisitação das páginas com que o jesuíta português quis fundamentar ou caucionar este papel, mediante um diálogo filosófico crítico com a mais conspícua tradição

2 Cf. Mário Santiago de Carvalho, O Problema da Habitação. Estudos de (História da) Filosofia (Lisboa: Edições Colibri - Faculdade de Letras da Universidade de Coimbra, 2002), 15-16.

3 Cf. Etienne Gilson, "Pourquoi Saint Thomas a critiqué Saint Augustin", Archives d'Histoire Doctrinale et Littéraire du Moyen Age 1 (1926-27), 5-127. 
referida. Se neste confronto esteve algo mais do que a oposição platonismo/ aristotelismo, a verdade é que o que dali resultou foi a inauguração de uma ação educativa absolutamente global totalmente baseada numa reflexão filosófica que não soube desprezar o que de mais atual havia no tempo - a herança de La Flèche em Descartes está aí para o demonstrar, ao menos no estrito campo da filosofia - assumindo sem pejo as ambições e as ânsias do seu tempo ${ }^{4}$. Na contraluz das palavras mais desalentadas com que iniciámos esta reflexão haveria então que acrescentar que a inauguração a que nos referimos representou, talvez sem o saber, uma pedra fundamental no edifício de uma endémica e grassante panescolarização. Neste quadro, impõe-se como desafio urgente pensar contra a escola.

2. Não se considera necessário retomar todas as conclusões do modelo encetado por Platão posteriormente adaptado por Agostinho. Se da ocasião da interrogação crítica pela ensinabilidade (didaktós) da areté (70a), questão académica e escolar desde o século $\mathrm{V}$, resulta algo é, naturalmente, a elevação de um tertium - a theia moira (99e) - em contraposição ao valor ou ao papel do que para nós hoje seria mais moderno ou mais plausível. O "exercício" e a "natureza" do tertium que irá ser recebido, repensado e propulsado, em solo cristão de crise cultural e social, despoletou um processo de interiorização (anámnesis), no sentido da denominada "doutrina do mestre interior". Desde logo, a resolução do paradoxo do ensino (anámnesis/mathesis) exibida por Platão nos termos da conclusão do diálogo - pode-se ensinar no sentido vulgar de uma transmissão de informações verdadeiras, mas o ensino só será autêntico se suscitar a reminiscência que culmina no processo da compreensão - será encenada por S. Agostinho no mais cúmplice amoroso intimismo qual, no fim de contas, um diálogo entre um pai e um filho, ambos concluindo que o verdadeiro ensino é o ensino (do/no) interior (III 14. 45). Da ágora passámos, nesse longínquo Ocidente do século $\mathrm{V}$ da nossa era, e sem que nada o fizesse crer, para a câmara, a partir de onde um retor como Agostinho decide interrogar com inusitada radicalidade a finalidade da linguagem (I $1.1 \mathrm{sg}$ ). Mas não obstante a alteração da topologia - da praça pública para a casa paterna -, por si, aliás, simbolicamente significativa, ambos os textos partilham uma ontologia genericamente "idealista" - palavra aqui utilizada em oposição a "materialista" - balizada pela desvalorização do sensível e o reforço do inteligível. Seria fácil traduzi-la mediante o próprio programa de Agostinho: a impotência e a vacuidade das palavras (signum) (X 10.33) frente à primazia da realidade (res) ideal. Mantém-se o paradoxo a que acima aludimos: a necessidade e utilidade dos sinais anuncia e denun-

${ }^{4}$ Cf. José Luís Fuertes Herreros, El discurso de los saberes en la Europa del Renacimiento y del Barroco (Salamanca: Ediciones Universidad de Salamanca, 2012). 
cia a sua própria impotência, mas dificilmente se poderia ser tão claro ou tão crítico a respeito da reduzida finalidade da escola e do que aí se pode ensinar/aprender no horizonte do que realmente importa pensar: “... quem será tão estultamente curioso, pergunta Agostinho, que mande o seu filho à escola para que ele aprenda o que o professor pensa? (...) Aqueles que são chamados discípulos consideram consigo mesmo se se disseram coisas verdadeiras, e fazem-no contemplando, na medida das próprias forças, aquela Verdade interior de que falámos..." (III 14.45; a tradução é de António Soares Pinheiro $)^{5}$.

Embora menos relevante, para o que aqui nos interessa, não poderíamos deixar de evocar pelo menos como o ápice desta perspetiva augustinista - a identificação da verdade interior com Cristo - encontrou em S. Boaventura o seu mais lídimo representante, nomeadamente no extraordinário sermão que o franciscano pronunciou na sua própria escola, a Universidade de Paris, "Unus est magister noster Christus" (1254?-1270?). Tratava-se, no fim de contas, de retomar o tema inequivocamente cristão da necessidade da ação iluminadora do Verbo caucionando a certeza do conhecimento humano. Nesse outro fantástico opúsculo seu, qual a Recondução da Ciências à Teologia, chega-se a ler uma passagem que explicita a relação entre os dois autores (retomamos a nossa tradução publicada em 1996): “... Agostinho conclui que só é verdadeiro doutor aquele que é capaz de imprimir a ideia, e infundir o lume, e dar virtude ao coração do ouvinte. E por isso é que 'tem a cátedra no céu aquele que ensina no íntimo dos corações'. Assim, pois, como nada é perfeitamente conhecido pela palavra a não ser por meio da virtude, do lume e da ciência unidas à alma, assim também, para que a alma seja instruída no conhecimento de Deus pela locução interna dele, é necessário que se una àquele "que é o esplendor da sua glória e a imagem da sua substância, e que tudo sustenta com o poder da sua palavra' (Heb. 1, 13)." Seguramente que para um olhar moderno e laico como o nosso, marcado pela separação de registos epistémicos, nada mais estranho do que a introdução do motivo cristocêntrico no pensamento e no horizonte da educação. Mas tratava-se, no fundo, não de menosprezar o papel do mestre exterior, mas sim de exaltar o magistério único e universal (doctor ministerialis), o que, aliás, tomado à letra, também parece colidir com a nossa usual ideologia secularizada, relativista e multiculturalista. Entretanto, se quiséssemos insistir numa eventual aquisição deste legado bastar-nos-ia evocar duas situações: a primeira, mais

5 Para uma reflexão sobre o autor, no quadro Pedagogia /Confissões, não podíamos deixar de remeter para a interessante proposta de Maria Teresa B. C. S. G. dos Santos, "Tempo e pedagogia em Santo Agostinho: um cruzamento em perspetiva", in: Tempo e Eternidade na Idade Média, org. Jan G. ter Reegen et. al. (Porto Alegre: Est Ed., 2007), $37-45$. 
epocal (mas que de qualquer modo nos vais interessar mais à frente), ligada à submissão do registo aristotélico ao registo augustinista; a segunda, com o seu quê de produtividade histórica, relativa, não tanto ao facto inconcusso de o tema vir a ser retomado pela filosofia moderna (mormente em Malebranche, apesar de logo criticado por Arnauld), quanto à inevitável e recorrente possibilidade, para não dizer exigência ou imperativo, de qualquer proposta mental e também educativa que se queira cristã não dever ou não poder ser ipso facto senão cristocêntrica.

Dito isto, facilmente se compreende como, para se instaurar uma filosofia moderna da educação, seria necessário inverter o registo assimétrico sinal/coisa ou, se quisermos, abrir a possibilidade à substituição das palavras pelas coisas mediante a inscrição de uma ontologia não semiótica. Um mundo finalmente naturalizado. (Apressemo-nos a anotar uma herança quiçá obsoleta mas da qual ainda partilhamos: uma filosofia da educação sem ontologia parece-nos uma fraude teórica e uma pueril e frágil ambição.) Responsável por esse movimento é Tomás de Aquino, a nosso ver. E a razão é fácil de explicar. Tratava-se tão-somente de alterar a teoria do conhecimento por anamnese, anulá-la se preciso fosse, gesto que deveria ser concomitante à adoção de uma ontologia das coisas esboçada numa doutrina da causalidade que conferisse ao mundo toda a autonomia que ele deve ter. É para tal que começa por contribuir o Aquinate nos quatro artigos da questão 11 das Quaestiones disputatae de Veritate, o seu próprio De magistro. Com efeito, este professor universitário - da praça pública ateniense passámos para o recesso do quarto e eis que nos encontramos enfim em plena sala de aulas, por nós tão bem conhecida hoje em dia - não podia ser mais claro ou mais frontal ao perguntar, logo a abrir a sua investigação (a. 1), se cabe ao Homem ou somente a Deus ser chamado mestre. Frente à tradição a novidade reside no facto de o Homem - um homem qualquer - passar doravante a ser considerado um mestre de pleno direito (a. 1 ad 9um), e esta novidade não é de somenos frente à história que acompanhámos até aqui, a da doutrina da recordação (Platão) e a da teoria do dador de formas (Avicena), também em causa como ensinou Gilson. Simplificando, ambas as soluções cairiam em erro, no ver do Aquinate, a de Avicena porque excluía as causas próximas, a de Platão/Agostinho porque tornava a ação (educativa) acidental e não essencial. De novo uma terceira via (a. 1 sol.), mas um tertium realmente novo - porque, na verdade, com a ousadia da retórica da inversão que voltaremos a encontrar em Nietzsche, afinal uma inversão daquela outra terceira via - na medida em que reivindica (na linguagem aristotélica compreensivelmente adotada) a ação do agente extrínseco próximo, quer dizer, do professor exterior frente ao mestre interior. S. Tomás de Aquino não volta as costas a este último (vd. a. 1 resp in fine) - os motivos religiosos e criacionistas continu- 
am a ser naturalmente pedra angular -, nem sequer recusa a preexistência de um conhecimento no educando em potência ativa, permitindo-lhe, uma tal destrinça no âmbito da potencialidade (ativa/passiva), precisar e situar o lugar da "descoberta", assim diferente do "ensino". Enfim, na nossa exegese, o que o dominicano avança é a própria naturalização do ensino ou a sua desteologização: “...o professor causa o conhecimento no aluno com a atividade da razão natural do aluno" (a. 1 sol.). Dito de outro modo, e ainda no mesmo artigo e lugar, mas com palavras assaz modernas para os nossos ouvidos: a lógica do ensino deve submeter-se à lógica da descoberta, sendo neste interstício de submissão como palavra proclamadora da criatividade, que se joga o papel e o estatuto do professor, todo o destino e missão do magistério: “... o professor deve conduzir o aluno ao conhecimento do que ele ignorava, seguindo o caminho trilhado por alguém que chega por si mesmo à descoberta do que não conhecia" (ibid.; os sublinhados serão sempre nossos e a trad. é de L. J. Lauand).

Será assim dito, sem quaisquer ambiguidades, que "o professor ensina o aluno"; mais ainda: que o seu papel é socialmente imprescindível - pois ninguém, propriamente falando, frisa T. de Aquino, se ensina a si mesmo (a. 2 sol.) -; e sobretudo: que a atividade docente em sentido preciso é mais perfeita (a. 2 ad 4um). De tudo isto decorrerá alfim o elogio do professor exterior ou do explícito pragmatismo da profissão docente competente e técnica: “...o professor, que explicitamente conhece todo o conteúdo, pode conduzir ao conhecimento de modo mais expedito do que o caminho daquele que por si mesmo se conduz ao conhecimento a partir dos princípios gerais" (ibid.). Uma outra passagem nuclear do Aquinate, na lógica da causalidade aristotélica, por um lado, e no quadro de um pragmatismo (de novo) moderno, é o artigo em que o frade dominicano, situando embora a atividade docente no âmbito da vida contemplativa - o fim da vida contemplativa é a Verdade -, se apressa a sublinhar que, na sua finalidade, o magistério pertence à vida ativa, transmitir alguma coisa a alguém (frise-se o destinatário como causa final, como é sabido a mais relevante na doutrina aristotélica das causas) (a. 4 sol.). Na ontologia naturalista das coisas, esta atividade tem contornos próprios, que são, ao fim e ao cabo, a contribuição do autor para a criação das condições filosóficas necessárias à instauração da didática, no âmbito de uma epistemologia aristotélica: o professor é o agente que ensina articulando causas e efeitos (a. 3 ad 4um); ademais, se isso não anula a intervenção do aluno - “... é necessário que o aluno vá conferindo os conceitos do professor a fim de que o processo na mente do aluno acompanhe o processo do conhecimento na mente do professor" (a. $3 \mathrm{ad} 4 \mathrm{um}$ ) - é porque "o professor causa o conhecimento no aluno com a atividade da razão natural do aluno" (a. 1 sol.). E como se processo tudo isto? Mediante a promoção e a aposta na 
descoberta dedutiva, também aqui em compreensível e justificável fidelidade à epistemologia aristotélica: “... aplicar princípios gerais e evidentes a determinadas matérias e daí chegar a algumas conclusões particulares, e destas, por sua vez, chegar a outras etc." (a. 1 sol.). É aliás pelo respeito a todo este processo epistémico-didático, pela sua evidência dedutiva a partir de princípios conhecidos, que o ensino se há de distinguir da opinião ou até mesmo da fé, conclui o autor (ibid.). Ou dito por palavras que quase parecem saídas de uma faculdade de educação do século XXI: o papel do professor no ensino reside em ajudar a "luz da razão" a atingir a perfeição do conhecimento (a. $1 \mathrm{ad} 9 \mathrm{um}$ ), quer dizer: autonomizar o ato de pensar, fazê-lo seu, apropriar-se de, para, enfim, permitir a descoberta com.

3. Entre os séculos XV e XVI, mas mais precisamente a partir da fantástica e inaudita iniciativa régia (D. João III) de pôr Coimbra no mapa educativo europeu, gesto de política esclarecida que a Companhia de Jesus procurou encarnar, aplicar e colonizar (na aceção geopolítica desta última atividade), surge o CAJC alicerçado, como convém, numa cada vez mais fundamentada e implicada visão sobre a prática educativa. E esta, numa ontologia e epistemologia rigorosas, dimensão que, repetimos, se nos impõe como uma exigência insuperável. Referimo-nos em particular ao de magistro conimbricense - chamemos-lhe assim - essencialmente plasmado no comentário aos Segundos Analíticos de Aristóteles, e mormente o seu capítulo 1 sobre os chamados "Praecognitis". A inscrição neste capítulo e locus aristotélico é desde logo significativa revelando-nos como a reflexão sobre a educação e a ensinabilidade enxerta-se num quadro epistemológico muito preciso concernente aos princípios da ciência ${ }^{6}$. $\mathrm{O}$ autor de toda esta discussão no CAJC, Sebastião do Couto, começa por questionar criticamente a relação entre "doutrina" e reminiscência (q. 1), a anterioridade ontológica e cognitiva das atividades da "doutrina" e da "disciplina" (q. 2), e avança depois para o exame exaustivo daquela mesma teoria (de praecognitis), chegando a ultrapassar o modo como Aristóteles a havia concebido (qq. 3 e 4) ? $^{7}$. Fá-lo não só porque tal era exigido pelo Estagirita, quer no quadro da ciência no seu todo, quer no quadro das ciências parcelares ${ }^{8}$, mas também porque a exposição

6 Vd. Mário Santiago de Carvalho, "A questão do começo do saber numa introdução à Filosofia do século XVI português”, in: Razão e Liberdade. Homenagem a Manuel José do Carmo Ferreira, AA.VV. (Lisboa: Centro de Filosofia da Universidade de Lisboa, 2010), 993-1009.

7 Cf. Amândio Coxito, Estudos sobre Filosofia em Portugal no século XVI (Lisboa: INCM, 2005), 323-353.

8 SaIc1q3a1p312. Para a identificação do título desta e de todas as restantes citações do CAJC, vd. Referências Bibliográficas, no final do presente artigo; após a indicação do 
do que importa conhecer previamente (praenoscenda) requeria a enunciação das divisões da prenoções (praenotio), tratadas, como se disse, no primeiro capítulo dos Segundos Analíticos ${ }^{9}$. Algumas palavras de explicação sobre este ponto, quiçá menos acessível hoje em dia. No quadro da epistemologia adotada como fundamento da problemática de magistro "prenoção" designa o conhecimento alcançado no quadro de uma relação de prioridade, de onde o prefixo pré (prae) que dá origem ao nome concreto primeiro conhecido ou precógnito (praecognitum) que, esclarece Couto, significa formalmente a prenoção e, denotativamente, aquilo que é pré-conhecido (praecognitum $)^{10}$. $\mathrm{Na}$ esteira de Aristóteles e como requisito respeitante ao quadro da ciência entendida na sua totalidade, é necessária a prenoção do que é (quid sit), ie, da natureza ou da essência ${ }^{11}$, do possível e do existente ${ }^{12}$. O Filósofo havia ainda enunciado três primeiros conhecidos (praecognita), o sujeito da demonstração, a as propriedades ou atributos demonstrados acerca do objeto-sujeito, e os princípios comuns necessários a toda a demonstração científica, ao que se acrescentaram pelo menos ainda mais dois, o termo médio e a consequência $^{13}$. E o que é ainda mais: seriam também três, por fim, os requisitos para se assentir nos princípios: uma clara perceção e evidência (penetratio) dos termos, a sua ligação ou conjugação numa forma proposicional, a aprovação de todo este conjunto ou juízo, o que constitui afinal o próprio conhecimento do princípio ${ }^{14}$. O tema de praecognitis fundamentaria assim claramente uma gramática e epistemologia dedutivas: os princípios devem ser mais conhecidos do que a conclusão ${ }^{15}$, ou de outro modo: o conhecimento do antecedente é a causa por si e a razão de assentir na conclusão ${ }^{16}$, o princípio está para as disciplinas, como o fim para as coisas naturais ${ }^{17}$.

Antes de avançarmos impõe-se evocar uma relevante e recente monografia sobre este contributo conimbricense sob a pena de um filósofo e historiador da educação, Cristiano Casalini (já o estudo de Amândio Coxito citado acima omite qualquer referência ao tema educativo). Seria ocioso, evidentemente, repisar o que ficou estabelecido de maneira competente, a saber (e

título a numeração romana remete para os livros em que as obras de Aristóteles habitualmente se dividem, e as demais abreviaturas desdobram-se intuitivamente, a saber: capítulo (c), explicação do capítulo (ex), questão (q), artigo (a), secção (s), página (p), Proémio (pr).

9 SaIc1exp288.

10 SaIc1q3a1p311.

11 SaIc1q3a3p316.

12 SaIc1q3a3s1p319; SaIc1q3a3s1p321.

13 SaIc1q3a2pp313-314.

14 SaIc1q2a3p309.

15 SaIc2exp344.

16 SaIc1q2a3p310.

17 PhIIc9exp349. 
em resumo abreviado ${ }^{18}$ : ao interpretarem o problema de magistro no quadro da exposição dos Segundos Analíticos - "Omnis doctrina, et disciplina ex antecedente cognitione fit" -, as páginas da Dialética atinentes a esse mesmo problema, superaram a doutrina de Santo Agostinho, mas também a de São Tomás. Sem deixar de sublinhar como aquele quadro epistemológico aristotélico se estenderá até Galileu (De precognitionibus et praecognitis), a Casalini deve ainda ser assacado o mérito de enquadrar toda esta problemática conimbricense no seu âmbito epocal e ideológico ou programático mais próximo, de Francisco de Toledo a Pedro da Fonseca designadamente, passando pelo também jesuíta Paulo Valla, fazendo-nos assim ver como Couto superou a tradição herdada - com participantes de relevo de permeio como Henrique de Gand ou Caetano - tomando em consideração o seu ambiente cultural e filosófico-cultural mais próximo, numa autêntica "filosofia da educação" (como dizemos hoje). Esta gravitaria em torno das figuras da doctrina e da disciplina, i.e., para simplificarmos, do ensino ou da aquisição da ciência perspetivada sob o ponto de vista da intervenção do professor e do aluno, respetivamente. Finalmente, ao desprezar a doutrina platónica da reminiscência, mas igualmente ao dar mais relevo do que São Tomás ao papel do docente, de acordo com o intérprete italiano, Couto quase fez coincidir o conhecimento humano, nas suas várias vertentes, com a educação: "A Dialética do Cursus fornece por isso as bases para uma doutrina da educação que se baseia na experiência, na comunicação entre mestre e discípulo, e que de facto supera o aristotelismo com um aristotelismo mais radical, em que se desvanecem todos os vestígios inatistas (...)", acabando Casalini por apontar que "o baixo contínuo da normatividade lógico-aristotélica dos jesuítas portugueses (...) será música para os ouvidos do século XVII francês, ávido de esprit de système (o texto foi adotado em La Flèche) e sobretudo para os ouvidos alemães, extraordinariamente sensíveis à harmonia da dialética e aos encantos da especulação pura"19.

Semelhante produtividade merece ser revisitada, como dissemos, e é patente que ela se inaugura, em Coimbra, prática ou aplicada, mas também teoricamente, opondo ao modelo da reminiscência (vigente no Ménon, no Fedro, em República X e em toda a escola neoplatónica) o programa de uma "nova inventio", oposição fundada na adoção da doutrina da alma como "tabula rasa" (a. 1 p291) e num hilomorfismo radical compatível com a infusão anímica criacionista (a. 2 p.293). Respondendo ao dilema do Ménon mediante a distinção entre conhecimento confuso e virtual e conhecimento formal e

18 Vd. Mário Santiago de Carvalho, "Duas recentes publicações sobre os Conimbricenses”, Revista Filosófica de Coimbra 23 (2014), 483-491.

19 Cristiano Casalini, Aristotele a Coimbra, Il 'Cursus' Conimbricensis e l'educazione nel 'Collegium Artium' (Roma: Anicia, 2012), 176-8. (A tradução é nossa) 
em si (a. 3 p.294), Couto concluirá que o mestre não infunde na mente do aluno a luz do intelecto ou as espécies inteligíveis, nem por si nem diretamente, mas ensina-o efetivamente no sentido em que lhe apresenta algumas asserções (pronuntiata) para que o intelecto do discente possa formar outras semelhantes, e lhe mostra sinais externos sensíveis, como o do exemplo, que auxiliem a mente do aprendiz para mais facilmente chegar ao conhecimento que se quer inculcar. Ainda e sempre tendo como pano de fundo o tema de praecognitis, esclarecer-se-á que tais sinais externos são conhecidos de modo confuso e universal pelo aluno, sendo-o, pelo professor, de modo particular e explicitamente ${ }^{20}$. A fim de se superar o dilema do Ménon, a distinção nuclear aqui é entre conhecimento virtual ou confuso, e formal, atual ou em $\mathrm{si}^{21}$, no seguinte sentido: sabe-se confusa ou virtualmente quando se conhecem os princípios de que as conclusões científicas dependem, mas tal não basta para se saber formalmente ou em si; para se saber formalmente ou em si o hábito da conclusão não é suficiente, são também necessários os princípios e o juízo do intelecto que deles infere a conclusão de maneira evidente ${ }^{22}$. E eis como o logos exterior parece ter toda a dimensão do espaço escolar, não podendo nós aqui deixar de assinalar uma vez mais como a história da evidência no Ocidente ainda carece de uma atenção dedicada à sua áulica encenação e alucinação ${ }^{23}$. Esse processo terá o seu desfecho no chamado conhecimento judicativo e enunciativo (notitia iudicativa/ notitia enunciativa), exigindo-se uma notícia judicativa para o ato de uma qualquer faculdade; concretizando: para o ato da vontade, a notícia do intelecto, e para o ato do apetite sensitivo, a notícia do sentido interno ${ }^{24}$. Porque na época o tema estava na agenda dos filósofos, em Coimbra defende-se ou sublinha-se com veemência a dimensão imprescindível de uma articulação rigorosa de uma linguagem investigativa e acolhedora da descoberta, desiderato este traduzido mediante a defesa de que a expressão cimeira do duplo género de "notícia" acabada de referir, o conhecimento intelectivo (notitia intellectiva), é sinónimo de conhecimento discursivo, devendo, a expressão 'disciplina dianoética', ie, 'racional', ser entendida como discursiva, ou seja, integrando o silogismo, a indução, o exemplo ${ }^{25}$.

Ao que fica dito importaria ainda somar a referida dupla abordagem da ciência ou saber, chamada a perspetiva da "disciplina" ou do aluno, e a pers-

20 SaIc1q1a3p295.

21 SaIc1exp290.

22 SaIc1q1a3p294.

23 Cf. Mário Santiago de Carvalho, "'Tremendos são os deuses quando aparecem às claras'. Notas sobre a Evidência, 'in memoriam Ferdinandi Gil”," in: A Razão Apaixonada. Homenagem a Fernando Gil, AA.VV. (Lisboa: INCM, 2008), 129-142.

24 AnIIIc13q4a2p431.

25 SaIc1q2a1p302. 
petiva da "doutrina" ou do docente; em palavras mais claras: a capacidade de aprender (disciplina) radica explicitamente na potência do ser humano ${ }^{26}$, a de ensinar (doctrina) depende da voz ou da escrita de um mestre ${ }^{27}$. Lembremo-lo: o CAJC é um texto para ser lido, antes de tudo o mais, mas também diremos, no fim, como o evento da voz respeita ao prazer de uma autoridade encarnada, e ipso facto geradora de escola e dos seus efeitos. Nada tendo que ver, como temos vindo a repisar, e igualmente Casalini e Coxito, com a reminiscência platónica, e sem deixar de se proclamar que a nobreza da doutrina se mede, quer pelo valor do tema ou da matéria, quer pelo grau de certeza $^{28}$, defender-se-á, sem quaisquer ambiguidades, frisemo-lo bem, que toda a aquisição do saber ou da ciência deve acontecer por uma descoberta temporal (nova inventio) ${ }^{29}$, em posição consonante com o entendimento da alma com uma tábua rasa na qual nada está inscrito ${ }^{30}$. Daqui que, literalmente fiel a este horizonte aristotélico, embora ultrapassando-o, também Manuel de Góis chame "mestre" àquele que comunica ao discípulo a ciência mediante exemplos sensíveis, por forma a reproduzir as imagens adequadas à inteleção, que lhe apresenta proposições comuns e princípios conhecidos, aplicando-os a conclusões particulares, como que levando-o pela mão ( $m a$ nuductio) para o conhecimento do inteligível e da verdade ${ }^{31}$. À semelhança, mas também diferentemente de uma ação física, dir-se-á que a ciência que está no discípulo é até de certo modo causada pelo mestre ${ }^{32}$.

Como dissemos, o hábito dos princípios é gerado pelo intelecto ${ }^{33}$ mas, não obstante a principal causa para neles assentirmos ser o também referido lume do intelecto, o acesso aos mesmos é cronologicamente indutivo; dito de outra maneira: o conhecimento dos princípios parte principalmente dos termos, mas sem experimento ou experimentação (experimentum) eles não são conhecidos perfeitamente ${ }^{34}$. Assim se há de compreender igualmente que, embora predominando um entendimento da ciência dedutiva, se não menoscabe a indução e a experiência sensível verdadeiramente compatível com a gnoseologia da tábua rasa. Este é um ponto relevante no século XVI, quer português, quer mesmo europeu. Devendo a experiência anteceder a in-

\footnotetext{
26 Igc3exp186.

27 SaIc1q2a1p301.

28 Saprp287.

29 SaIc1q1a1p291.

30 SaIc1q1a2p293.

31 AnIIc1q7a3p83.

32 SaIc1q2a1p301.

33 SaIc1q1a4p300.

34 SaIc1q2a3p308.
} 
dução, e ainda concorrendo como condição do princípio ${ }^{35}$, apesar de ambas se identificarem no objeto, porque as duas versam sobre o singular, o CAJC distingue a experimentação da indução, porquanto com esta se pode apesar de tudo alcançar o universal, enquanto que aquela, mesmo na sua vertente possível de juízo do intelecto, versa sobre uma coisa singular conhecida sensivelmente ${ }^{36}$.

A doutrina da ciência entrecruza-se com a da arte (aliás de certo modo sinónimas, ars e scientia ${ }^{37}$ ), em cuja vitalidade tudo se aposta, no quadro do espírito renascimental assaz sensível à dignidade do Homem. Desta feita, repetindo-se um lugar comum na discussão, mormente propalado por Tomás de Aquino, e respeitante à analogia pedagogia/medicina, dir-se-á que, tal como acontece nesta última, ao aplicar ao passivo os princípios naturais ativos (naturalia ativa), a arte pode realizar muitas coisas na natureza ${ }^{38}$, fazer muito a partir da natureza ${ }^{39}$, aperfeiçoar a própria natureza ${ }^{40}$. Na verdade, é a equivalência eventual entre natureza do Homem e educação que aqui começa a equacionar-se ou a ser incoada. E se Pedro da Fonseca escorou a capacidade de aprender (hominem esse disciplinae capacem) na essência do ser humano ${ }^{41}$, Góis, por seu lado, preferirá comparar o génio ou o talento (ingenia) dos homens às árvores que dobram, domesticando-se pelas ciências (ars) e pela educação (cultus) ${ }^{42}$; nas palavras tão ingenuamente entusiastas dos dois jesuítas ligados à iniciativa do CAJC: por ser capaz de aprendizagem $^{43}$, o Homem é uma árvore celeste ${ }^{44}$.

Não poderíamos terminar o enquadramento mais geral para uma aproximação cabal à "filosofia da educação" conimbricense sem, por último, evocarmos a doutrina do "habitus", a apropriação coimbrã da "hexis" aristotélica

\footnotetext{
35 SaIc1q2a2p305.

36 SaIc1q2a2p307.

37 Diprp1.

38 PhIIc1q6a2p235.

39 PhIIc1q5a1p231.

40 PhIIc1q5a2p232.
}

41 Pedro da Fonseca, Instituições Dialéticas. Institutionum Dialecticarum Libri Octo, II, 2, introdução, estabelecimento do texto, tradução e notas por Joaquim Ferreira Gomes (Coimbra: Universidade de Coimbra, 1962), 97: «Com efeito, se alguém negar que o Homem é capaz de educação, é lógico que negue que ele é Homem»; vd. Mário Santiago de Carvalho, "The Coimbra Jesuits' Doctrine on Universals (1577-1606)", Documenti e Studi sulla Tradizione Filosofica Medievale. An International Journal on the Philosophical Tradition from Late Antiquity to the Late Middle Ages of the 'Società Internazionale per lo Studio del Medioevo Latino' (S.I.S.M.E.L.) 18 (2007) 531-543.

42 CoIIc3q9a3p193.

43 Igprq1a2p64.

44 GcIIc8q4a2p454. 
mormente em clave antropológica. Inferior em nobreza aos atos ${ }^{45}$, e superior à mera disposição, o que caracteriza o hábito é a sua constância (diuturnior), a dificuldade em ser retirado do sujeito, tal os casos da ciência e da virtude ${ }^{46}$. Nele cabem todas as espécies impressas do intelecto e dos sentidos internos, com exceção do sentido comum, todas as artes, virtudes e ciências, além de todas as qualidades do corpo e da alma decorrentes de um uso frequente, de uma disciplina, diríamos nós na linguagem moderna da física do corpo ${ }^{47}$. Os hábitos intelectivos - entendimento (intellectus), a ciência, a sabedoria, a prudência e a arte são hábitos intelectivos, em parte pertencentes à filosofia natural, em parte à moral, enquanto esta considera as ações da alma conducentes à probidade da vida e atinentes à felicidade natural ${ }^{48}$ - distinguem-se naturalmente dos hábitos práticos. Por seu lado, prudência e arte dizem respeito ao intelecto prático ${ }^{49}$, e a divisão aqui em causa concerne à inclinação do intelecto para o assentimento nas verdades especulativas, mas também à possibilidade de se alcançar o bem, daí o nome equivalente de sindére$\mathrm{se}^{50}$. Embora a ação moral da virtude seja acidentalmente breve, por si, ela é arraigada ${ }^{51}$. Tudo isto é no fim de contas linguagem técnica epocal para ampliar uma "filosofia da educação" ao seu destinatário óbvio, dimensão que se articula em Coimbra, como estamos a ver, mediante a conjugação de uma ontologia com uma epistemologia e a sua inesperada aplicação a uma antropologia situada ou encarnada. Por isso, ainda no plano dos hábitos, a disposição contemplativa para as virtudes intelectivas consiste na afirmação firme e evidente dos primeiros princípios e das proposições analíticas, na ciência e na sabedoria ${ }^{52}$. Importa deixar bem sublinhado que a disposição para as ciências no ser humano não é inata ${ }^{53}$, e bem assim a disposição para os primeiros princípios ${ }^{54}$. E a mesma lição se extrairia no quadro do que se conhece previamente (o tema de praecognitis, de novo), porquanto é de uma maneira adquirida que detemos os hábitos dos primeiros princípios. Eles não são infundidos, nem por Deus, nem pela natureza, mas são adquiridos, pelos hábitos precisamente ${ }^{55}$. E um momento curioso desta extensão ou aplicação da epistemologia para a antropologia encarnada é, decerto, a utilização de

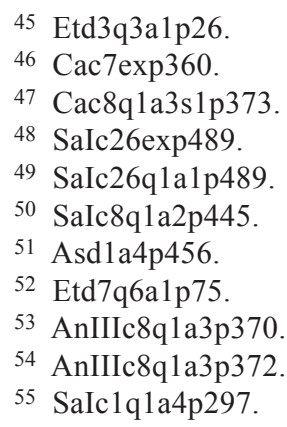


dois vocábulos relacionados com o prazer: diversão (recreatio), sobre a qual se lê que a audição é mais agradável do que a leitura ${ }^{56}$ (repita-se que era esse justamente o destino do CAJC), e alegria (iucunditas), indissociável do prazer da aprendizagem (discere) ${ }^{57}$.

Finalmente, e como muito bem estabeleceu Coxito no estudo que citámos, a abertura à indução e à experiência não significou abdicar do modelo ideal de uma ciência dedutiva. A modernidade desta constância, defendemos nós, não se avaliará no confronto coimbrão com o empirismo, mas com o apriorismo que culminará em Kant. Ora, mesmo nesta perspetiva, ou sobretudo nela, a experiência e o mundo da indução não são causa, mas condição, não são fundamento, mas indispensabilidade, não são necessidade, mas legitimação (mais ontológica do que lógica). E acresce, só para acabarmos, por enquanto em tom positivo, que o que poderia desembocar afinal numa nova retórica foi antes superado por uma consistente filosofia da ciência apostada em compatibilizar a necessidade da experiência com o vetor racional (habitus) das ciências e das artes ${ }^{58}$.

4.

O CAJC contribuiu decisivamente para que a importância da discussão sobre o mestre interior não impedisse a entrada de um dos principais autores da cena pedagógica, o mestre exterior (na linguagem medieval herdada e tão incisiva). O professor, tal como o conhecemos, impunha-se assim graças a uma dada obliteração de Deus, e em breve ocupando já plenipotenciariamente o lugar da sabedoria, mas o aluno, enquanto tal, só surgirá ali onde o aprofundamento radical da complexa tarefa do professor se enxerta numa explícita adoção de uma filosofia fundamental. Foi este o mérito e a modernidade de Coimbra nos séculos XVI e XVII e a sua interpelação continua

56 Qcs2p548.

57 Qcs3p553.

58 Não resistimos a reproduzir, com a devida vénia, a tradução de uma passagem do Proémio da Dialética conimbricense, pela mão de A. Coxito, no seu artigo já citado (p. 352-53): "Afirma-se com propriedade que a experiência gerou as artes e as ciências (...). Com efeito, pela experiência confirma-se, por exemplo, que o ruibarbo curou a cólera de Sócrates, de Platão, de Cálias e de outros. A partir desta verificação, formou-se um conhecimento universal e um juízo acerca do ruibarbo, dizendo-se que ele cura a cólera. Assim, para criar a arte argumenta-se desta maneira: àqueles que padeciam de cólera administrou-se um remédio para curá-la; mas o ruibarbo curou a cólera; por conseguinte, deve ser administrado a quem padece dessa doença. Nesta argumentação, o hábito que permaneceu na mente pelo assentimento à conclusão 'o ruibarbo deve ser administrado a quem padece de cólera' designa-se por 'arte'. E tal hábito gerou-se com base numa experiência anterior (...). O mesmo acontece na aquisição das outras artes e nas ciências, em cada uma a seu modo." 
vigente, quiçá cada vez mais. Porém, se o registo da horizontalização, da naturalização e do relativismo da Verdade, mediante a ficção de dois absolutos intervenientes que progressivamente se impuseram à relatividade da cena escolar, parece ter ganhado tanto em tecnicismo - o mesmo que, entre outros níveis menos deletérios, acabará por justificar a colonização panescolarizadora - ele perdeu naquilo que realmente importa pensar, a Diferença que interpela e constitui o Humano, este sobrevivendo agora sob a obscura ameaça de desumanização. É porque o século XXI parece ignorar a relatividade enunciada que urge pensar contra a Escola.

\section{Referências Bibliográficas:}

Commentarii in libros Aristotelis Stagiritae de Posteriore Resolutione, in Commentarii Collegii Conimbricensis e Societate Iesu, In universam Dialecticam Aristotelis Stagiritae. Coimbra, 1606, pp. 285-524. [Abreviado supra: Sa]

Commentarii in libros Categoriarum Aristotelis Stagiritae [Comentário aos Livros das Categorias], in Commentarii Collegii Conimbricensis e Societate Iesu, In universam Dialecticam Aristotelis Stagiritae. Coimbra, 1606, pp. 226-416. [Abreviado supra: $\mathrm{Ca}$ ]

Commentarii Collegii Conimbricensis e Societate Iesu, In universam Dialecticam Aristotelis Stagiritae. Coimbra, 1606. [Abreviado supra: Di]

Commentarii Collegii Conimbricensis Societatis Iesu, In tres libros de Anima Aristotelis Stagiritae. Coimbra, 1598. [Abreviado supra: An]

Commentarii Collegii Conimbricensis Societatis Iesu, In Octo Libros Physicorum Aristotelis Stagiritae. Coimbra, 1592. [Abreviado supra: $\mathrm{Ph}$ ]

Commentarii in Isagogem Porphyrii, in Commentarii Collegii Conimbricensis e Societate Iesu, In universam Dialecticam Aristotelis Stagiritae. Coimbra, 1606, pp. 55-225. [Abreviado supra: Ig]

Commentarii Collegii Conimbricensis Societatis Iesu, In duos libros De Generatione et Corruptione Aristotelis Stagiritae. Coimbra, 1597. [Abreviado supra: Gc]

In libros Ethicorum Aristotelis ad Nicomachum, aliquot Conimbricensis Cursus Disputationes in quibus praecipua quaedam Ethicae disciplinae capita continentur. Lisboa, 1593. [Abreviado supra: Et]

Commentarii Collegii Conimbricensis Societatis Iesu, In Quatuor libros de Coelo Aristotelis Stagiritae. Lisboa, 1593. [Abreviado supra: Co]

Tractatio aliquot Problematum ad quinque sensus spectantium per totidem sectiones distributa, in Commentarii Collegii Conimbricensis Societatis Iesu, In tres libros de Anima Aristotelis Stagiritae. Coimbra, 1598, pp. 533-558. [Abreviado supra: Qc]

Tractatus de Anima Separata, in Commentarii Collegii Conimbricensis Societatis Iesu, In tres libros de Anima Aristotelis Stagiritae. Coimbra, 1598, pp. 441-536. [Abreviado supra: As] 
Platon, Oeuvres Complètes: Gorgias, Ménon, texte établi et traduit par A. Croiset, avec la collaboration de L. Bodin. Paris : Les Belles Lettres, 1949.

Platon, Ménon, traduction inédite, introduction et notes par M. Canto-Sperber. Paris: Flammarion, 1993.

Saint Augustin, Oeuvres de Saint Augustin : Dialogues Philosophiques - De Magistro, texte, traduction et notes par F.-J. Thonnard. Paris : Desclée de Brouwer, 1941.

Santo Agostinho, O Mestre, introdução e comentários de $\mathrm{M}^{\mathrm{a}}$ Leonor Xavier, tradução de António Soares Pinheiro. Porto: Porto Editora, 1995.

Saint Bonaventura, Le Christ Maître, édition, traduction et commentaire du sermon universitaire "Vnus est magister noster Christus" par G. Maldec. Paris: J. Vrin, 1990.

São Boaventura, Recondução das Ciências à Teologia, tradução e posfácio de Mário Santiago de Carvalho. Porto: Porto Editora, 1996.

Saint Thomas d'Aquin, De Magistro "de l'enseignement», introduction, traduction et notes de B. Jolibert. Paris: Klincksieck, 1999.

Thomas d'Aquin, Quaestiones disputatae. vol. I: De Veritate, cura et studio R. Spiazi. Turim-Roma: Marietti, 9a ed., 1953.

Tomás de Aquino, Sobre o Ensino (De Magisto). Os Sete Pecados Capitais, tradução e estudos introdutórios de Luiz Jean Lauand. São Paulo: Martins Fontes, 2001.

Código Pedagógico dos Jesuitas. 'Ratio Studiorum'da Companhia de Jesus [1599]. Regime Escolar e Curriculum de Estudos, prefácio de Luiz Fernando Klein, S.J., nota prévia, introdução versão portuguesa e notas de Margarida Miranda. Lisboa: Esfera do Caos, 2009.

Leitão, H. \& Franco, J.E. (orgs.), Jesuitas, Ciência e Cultura no Portugal Moderno. Obra Seleta de P. João Pereira Gomes, S.J. Lisboa: Esfera do Caos, 2012.

Vicente, J. das Neves. Educação, Retórica e Filosofia a partir de Olivier Reboul: subsidios para uma filosofia escolar. Tese de doutoramento em Filosofia, Coimbra, 2008. 